\title{
Modulation of Central Cholinergic Activity by GABA and Serotonin: PET Studies with ${ }^{11} \mathrm{C}$-Benztropine in Primates
}

Stephen L. Dewey, Ph.D., Gwenn S. Smith, Ph.D., Jean Logan, Ph.D., and Jonathan D. Brodie, Ph.D., M.D.

The pharmacologic treatment of many neuropsychiatric disorders (Alzheimer's disease, schizophrenia, depressive illness) has been targeted at the central hypothesis that defects in a single neurotransmitter system underlie the pathophysiology of the disease state. With the recognition that such treatments have not been efficacious consistently, recent drug development has been directed at altering other functionally linked neurotransmitters inoolved in these diseases. Using positron emission tomography, we have noninvasively investigated the effects of two noncholinergic drugs on the release of acetylcholine. By examining the effects of gamma-vinyl gamma-aminobutyric acid (GABA) (a GABA transaminase inhibitor) or altanserin (a serotonergic antagonist) on the regional binding of ${ }^{11} \mathrm{C}$-benztropine in the primate brain (Papio anubis), we demonstrated that drugs acting upon either GABAergic or serotonergic neurons produce profound regional changes in acetylcholine release. These findings indicate that the mechanisms of action and the subsequent therapeutic efficacy of these centrally acting drugs may be linked to their multitransmitter effects. This application of positron emission tomography represents an extremely promising experimental approach that can be directed towards elucidating abnormalities in neurotransmitter modulation relevant to disease progression and pharmacologic treatment. [Neuropsychopharmacology 8:371-376, 1993]
KEY WORDS: Benztropine; GABA; Serotonin; Interactions; Positron emission tomography; Altanserin; Gamma-vinyl GABA

\section{INTRODUCTION}

Monitoring changes in synaptic neurotransmitter conœntrations can provide insight into the neurophysio-

\footnotetext{
From the Department of Chemistry, Brookhaven National Laboratory (SLD, JL), Upton, New York and the Department of Psychiatry, New York University School of Medicine (GSS, JDB), New York, New York 10016

Address correspondence to: Stephen L. Dewey, Ph.D., Department of Chemistry, Brookhaven National Laboratory, Upton, New York 11973.

Received September 30, 1992; revised January 15, 1993; accepted January 22, 1993.
}

logic mechanisms underlying the central nervous system's (CNS) ability to control many biologic, behavioral, and neurohumoral processes. Upon loss of this ability, specific behavioral manifestations, historically attributed to single neurotransmitter systems, may result. For example, Parkinson's disease (Bernheimer et al. 1973) and schizophrenia (Seeman et al. 1987) have been linked to alterations in the dopamine system and the cognitive deficits of Alzheimer's disease (AD) have been linked to alterations in the cholinergic system (Davis and Maloney 1976; Bartus et al. 1982). However, subsequent neurochemical analyses of postmortem tissue in these disease states have demonstrated alterations in other functionally linked neurotransmitters. Therefore, the clinical progression of these illnesses may result from the inability of the neurotransmitter initially affected to modulate or be modulated by other neurochemical systems. To address these issues clinically, 
an experimental approach must be developed and validated that can be used on the human brain in vivo to simultaneously manipulate and quantitate fluctuations in synaptic neurotransmitter concentrations resulting from a wide variety of neurophysiologic mechanisms.

Positron emission tomography (PET) is rapidly emerging as an effective imaging technique for quantitating not only cerebral metabolic rates of glucose or regional cerebral blood flow but many aspects of neuronal physiology as well (for review, see Phelps et al. 1986). For example, PET has been used to monitor changes in the synaptic concentrations of the neurotransmitters, dopamine (DA) and acetylcholine ([ACh] Dewey et al. 1990a). Whether induced directly (Dewey et al. 1991, 1993) or indirectly through interactions with other neurotransmitter systems (Dewey et al. 1990a, $1992 a, b)$, these changes were reflected in regional decreases in the binding of either ${ }^{11} \mathrm{C}$-benztropine $(\mathrm{ACh})$ or ${ }^{11} \mathrm{C}$-raclopride (DA) following pharmacologic manipulation. Gamma-aminobutyric acid (GABA) and serotonin (5-HT), however, have been shown to influence the release of these two neurotransmitters as well (Jackson et al. 1988; Scatton and Bartholini 1980). Having recently demonstrated that GABA and 5-HT inhibit the release of striatal DA (Dewey et al. 1992a,b), we extended these findings to an examination of the role that GABA and 5-HT play in regulating synaptic ACh release in the primate brain. Although this approach provides clinically significant information relevant to the design of new and innovative treatment strategies for cholinergic defect states such as $\mathrm{AD}$, it also provides a clear demonstration of PET's unique ability to examine the multiple mechanisms of action of centrally acting therapeutic agents.

In the present study we performed paired PET scans using ${ }^{11} \mathrm{C}$-benztropine, a muscarinic cholinergic ligand (nonselective for the muscarinic receptor subtypes) whose binding characteristics have been measured (Dewey et al. 1990b). The first scan served as a control for the second that occurred following pretreatment with gamma-vinyl GABA (GVG), a specific sui- cide inhibitor of the GABA-catabolizing enzyme GABA transaminase ([GABA-T] EC 2.6.1.19, Schechter et al. 1977) or altanserin, a relatively selective $5-\mathrm{HT}_{2}$ antagonist that has recently been radiolabeled with fluorine-18 and used with PET to study the regional distribution of $5-\mathrm{HT}_{2}$ receptors in the human brain (Lemaire et al. 1991).

\section{MATERIALS AND METHODS}

Adult female baboons (Papio anubis) weighing between 13 and $18 \mathrm{~kg}$ were prepared for dynamic PET scanning in a Computer Technologies Imaging positron tomograph (model 931-08/12; 15 slices, 6.5-mm slice thickness, full width at half maximum [FWHM], $6.0 \times 6.0$ $\mathrm{mm}$ in plane resolution). Scanning commenced at isotope injection and continued for 84 minutes using the following scanning protocol: four scans for 15 seconds followed by two scans for 30 seconds followed by four scans for 1 minute followed by four scans for 2 minutes followed by five scans for 10 minutes followed by one scan for 20 minutes. Arterial blood was sampled throughout the scanning period and selected plasma samples $(1.0,5.0,10.0$, and 30.0 minutes) were analyzed for the presence of unchanged ${ }^{11} \mathrm{C}$-benztropine as described previously (Dewey et al. 1990b). All animals, studied at the same time in their estrous cycle, were immobilized initially with ketamine $(10 \mathrm{mg} / \mathrm{kg}$, intramuscularly) and were subsequently maintained at a constant level on gaseous anesthesia (isoflurane, $\mathrm{n}$ trous oxide, and oxygen) for the duration of the studies. In all studies, sequential injections of ${ }^{11} \mathrm{C}$-benztropine (2.00 to $15.00 \mathrm{mCi}$, Specific Activity 750 to 1500 $\mathrm{mCi} / \mu \mathrm{mol})$, were performed on the same day. Gammavinyl GABA was intravenously administered at a dose of $300 \mathrm{mg} / \mathrm{kg} 180$ minutes prior to the second isotope injection $(n=3)$. Altanserin was intravenously administered at a dose of $1.0 \mathrm{mg} / \mathrm{kg} 45$ minutes prior to the second isotope injection $(n=3) .{ }^{11} \mathrm{C}$-benztropine was synthesized as described previously (Dewey et al.

Table 1. Distribution Volumes for ${ }^{11} \mathrm{C}$-Benztropine Following GVG Pretreatment

\begin{tabular}{|c|c|c|c|c|c|c|c|c|c|c|}
\hline Study & ST & \% Chg & FC & \% Chg & CB & $\%$ Chg & ST/CB & \% Chg & FC/CB & $\%$ Chg \\
\hline $\begin{array}{l}186 \mathrm{~A} \\
186 \mathrm{~B}\end{array}$ & $\begin{array}{r}16.7 \\
3.60\end{array}$ & -78 & $\begin{array}{l}5.13 \\
3.86\end{array}$ & -25 & $\begin{array}{l}3.23 \\
3.53\end{array}$ & 9.3 & $\begin{array}{l}5.17 \\
1.02\end{array}$ & -80 & $\begin{array}{l}1.58 \\
1.09\end{array}$ & -31 \\
\hline $\begin{array}{l}187 \mathrm{~A} \\
187 \mathrm{~B}\end{array}$ & $\begin{array}{l}49.5 \\
32.6\end{array}$ & -34 & $\begin{array}{l}18.8 \\
13.7\end{array}$ & -27 & $\begin{array}{l}13.0 \\
12.2\end{array}$ & -6.2 & $\begin{array}{l}3.81 \\
2.67\end{array}$ & -30 & $\begin{array}{l}1.45 \\
1.12\end{array}$ & -23 \\
\hline $\begin{array}{l}202 A \\
202 B\end{array}$ & $\begin{array}{l}22.4 \\
15.6\end{array}$ & -30 & $\begin{array}{l}18.6 \\
12.8\end{array}$ & -31 & $\begin{array}{l}13.2 \\
12.0\end{array}$ & -10 & $\begin{array}{l}1.70 \\
1.30\end{array}$ & 24 & $\begin{array}{l}1.41 \\
1.07\end{array}$ & -24 \\
\hline
\end{tabular}

A refers to the control study.

$B$ refers to the second study performed 90 minutes posttreatment.

$\mathrm{ST}=$ striatum; FC = frontal cortex; $\mathrm{CB}=$ cerebellum. 
1990b). Animals remained in the tomograph between isotope injections to minimize changes in head position. Movement of the animal's head during the scanning period was also monitored with an infrared monitoring device (Tri-Tronics, Smarteye model SD). Vital signs and body temperature were monitored throughout the scanning period and animals recovered for at least 3 weeks prior to their next study.

Regions of interest (ROI's) were drawn directly on the PET images using software supplied with the tomograph as detailed previously (Dewey et al. 1992b). Receptor availability as a function of changes in synaptic

technique specifically designed for reversible systems that directly gives a linear function of the free receptor concentration known as the distribution volume ([DV] Logan et al. 1989; Koeppe et al. 1991). Recent studies with ${ }^{11} \mathrm{C}$-flumazenil, a reversible benzodiazepine antagonist, have shown that the use of the DV for this compound makes it possible to separate high-affinity binding from altered radioligand delivery due to changes in regional cerebral blood flow (Holthoff et al. 1991). We present results for the striatum, cortex, and cerebellum as well as the ratio of the striatum to the cerebellum and cortex to cerebellum, as these ratios do not contain the term K1/k2 (transport constants).

\section{RESULTS}

Immediately following isotope injection, radioactivity began to accumulate throughout all cortical and subcortical gray structures. There was no accumulation of radioactivity in any white matter region. With the exception of the thalamus and cerebellum, which began to clear of radioactivity within 20 minutes, radioactivity reached a peak uptake within 60 minutes and cleared slowly over the remainder of the scanning period. This regional and temporal pattern of distribution closely paralleled our previous findings with ${ }^{11} \mathrm{C}$-benztropine in the primate brain (Dewey et al. 1990b). There was no detectable movement of the animal's head during any of the scanning procedures. Administration of GVG or altanserin did not produce changes in any of the monitored vital signs or in any animal's core temperature, and the specific activity of the radiotracer did not vary significantly within the same day. In all cases, recovery from anesthesia was unremarkable.

Regionally specific alterations in ${ }^{11} \mathrm{C}$-benztropine binding were observed following GVG and altanserin administration. Gamma-vinyl GABA produced quantitative decreases in the ratio of the DV's in both the striatum (44\%) and cortex (26\%) but had no effect on either thalamic or cerebellar uptake (Table 1). In contrast, altanserin only reduced the ratio of the striatum/cerebellum DV (32\%) and had no effect on the cortical, thalamic, or cerebellar uptake (Table 2). Neither GVG nor altanserin altered the rate of the systemic metabolism of ${ }^{11} \mathrm{C}$-benztropine or the metabolite corrected plasma input function. These decreases exceed the test/retest variability of this radiotracer performed in the same animals under identical experimental conditions (less than 10\%, Dewey et al. 1990b).

\section{DISCUSSION}

The regional decreases we observed in radiotracer binding in response to pharmacologic challenge demonstrate the first use of PET for noninvasively monitoring increases in the synaptic concentrations of neurotransmitters whether induced directly (Dewey et al. 1991, 1993) or indirectly through interactions with other functionally linked systems (Dewey et al. 1990a, 1992b). However, if these PET radiotracers are sensitive to changes in synaptic neurotransmitter concentrations, then their binding should not only decrease but increase following depletion of their endogenous competitors as well. Recently, we examined GABA's role in modulating striatal DA release by pretreating animals with GVG and performing paired PET scans with ${ }^{11} \mathrm{C}$-raclopride. ${ }^{11} \mathrm{C}$-raclopride binding increased significantly from control levels following GVG administration, indicating that endogenous DA levels decreased (Dewey,

Table 2. Distribution Volumes for ${ }^{11} \mathrm{C}-$ Benztropine Following Altanserin Pretreatment

\begin{tabular}{lcccccc}
\hline Study & ST & \% Chg & CB & \% Chg & ST/CB & \% Chg \\
\hline 212A & 21.4 & & 7.71 & & 2.78 & \\
212B & 16.2 & -24 & 9.30 & 21 & 1.74 & -37 \\
225A & 22.0 & & 7.00 & & 3.14 & \\
225B & 15.0 & -32 & 7.00 & 0.0 & 2.14 & -32 \\
218A & 40.0 & & 14.2 & & 2.82 & \\
218B & 27.0 & -33 & 12.1 & -15 & 2.23 & -21 \\
\hline
\end{tabular}

A refers to the control study.

$B$ refers to the second study performed 45 minutes posttreatment.

$\mathrm{ST}=$ striatum, $\mathrm{CB}=$ cerebellum . 
et al., 1992b). This is consistent with GABA's known ability to decrease synaptic concentrations of DA (Stevens et al. 1974). In the present study we extended these findings to an examination of the roles of GABA and 5-HT in modulating $\mathrm{ACh}$ release in vivo.

The dorsal and median raphe nucleus are the major sources of 5-HT in the CNS. Serotonin-2 receptors have been localized to cortical cholinergic nerve terminals as revealed by the loss of these receptors secondary to lesions of the nucleus basalis of Meynert (Quirion and Richard, 1985). Serotonergic innervation to the striatum is derived from the dorsal and medial raphe nuclei, which project to the striatum, pallidum, and substantia nigra (mainly the pars compacta). Serotonin has been shown to inhibit striatal ACh release (Euvrard et al. 1977; Guyenet et al. 1977) and depletion of endogenous 5-HT increased ouabain-stimulated release of striatal ACh (Vizi et al. 1977). Gillet and coworkers (1985) demonstrated that exogenously administered 5-HT, 5-HT agonists, or fluoxetine, an inhibitor of 5-HT uptake, reduced striatal $\mathrm{ACh}$ release, whereas methysergide, a 5-HT antagonist, increased ACh efflux in the caudal striatum (Jackson et al. 1988). However, Robinson (1983) found no effect of 5-HT on striatal ACh levels but instead reported an inhibition of $\mathrm{ACh}$ in cortex and hippocampus.

Altanserin decreased ${ }^{11} \mathrm{C}$-benztropine binding by $29 \%$ in the striatum (Table 2); although consistent with some findings, it is inconsistent with the findings of Robinson. One possible explanation may lie in the fundamental differences between the techniques used to measure neurotransmitter release and those used to induce the changes (e.g., neurochemical lesions versus pharmacologic blockade). Following lesion of the raphe nucleus, Robinson examined $\mathrm{ACh}$ turnover rates in postmortem tissue by examining the slope of the firstorder decay plots of $1 \mathrm{n}(\mathrm{ACh})$ versus time after the inhibition of ACh synthesis by hemicholinium-3 (HC-3). Rats were sacrificed by microwave irradiation at 10,20 , and 30 minutes following HC-3 administration. Our PET studies, however, were performed in primates in vivo by measuring decreases in the binding of ${ }^{11} \mathrm{C}$ benztropine in response to $5-\mathrm{HT}_{2}$ blockade. The results of this approach, although representing the only noninvasive methodology currently available for making quantitative measurements in the human brain, must be interpreted within the confines of the technique. For example, a radiotracer with a low affinity (high $K_{d}$ ) for a specific receptor type will be more sensitive to changes in its endogenous competitor than one with a higher affınity (low $K_{d}$, Seeman et al. 1989). Benztropine's $K_{d}$ is 4 to $7 \mathrm{nmol} / \mathrm{L}$ for the muscarinic M1 and M2 site, respectively (Snyder and Yamamura 1977). Therefore, small increases in ACh content that may have occurred following altanserin pretreatment, might not produce measurable changes in ${ }^{11} \mathrm{C}$-benztropine binding. Fur- thermore, unlike postmortem studies, PET measurements are performed in live subjects. Therefore, these changes are influenced not only by the direct effects of the drug administered but also by the indirect effects the drug may have on other neurotransmitter and neurohumoral systems. Finally, the relationship between the time of drug administration and the time and duration of PET scanning is extremely important. In the present study, PET scanning began 45 minutes following altanserin administration and continued for 84 minutes. It is conceivable that this difference alone might explain this discrepancy as cortical increases in ACh may have occurred sooner than those in the striatum. Conversely, there may be differential time courses for compensatory responses that regulate synaptic $\mathrm{ACh}$ activity for cortex and striatum.

The ventral pallidum receives direct input from ventral striatal regions that contain a large number of GABAergic neurons (Heimer and Wilson 1975). It is unknown, however, whether this GABAergic input originates from these striatal GABAergic neurons or whether it arises from axons of other projection or GABAergic interneurons. Unlike the findings reported with 5-HT, GABA and GABA mimetic agents such as muscimol and SL 76002 have been shown to produce an increase in striatal $\mathrm{ACh}$ content, the largest of which was observed in the rat striatum with smaller effects in the cortex, nucleus accumbens, olfactory tubercle, hippocampus, interpeducular nucleus, hypothalamus, and brainstem (Scatton and Bartholini, 1980). Furthermore, Cosi and Wood (1988) showed a lack of GABAergic modulation of thalamic $\mathrm{ACh}$ release, consistent with neuroanatomic findings.

Gamma-vinyl GABA produced a regionally specific decrease in ${ }^{11} \mathrm{C}$-benztropine binding. Striatal binding decreased $47 \%$ and cortical binding decreased $28 \%$. There were no changes observed in the thalamus or cerebellum. These regional and quantitative changes are consistent with GABA's reported excitatory role in striatal and cortical ACh release (Scatton and Bartholini, 1980; Bonanno and Raiteri, 1988). Taken with our previous work using ${ }^{11} \mathrm{C}$-raclopride and GVG (Dewey, et al., 1992b), this study represents the first demonstration with PET that a single drug (GVG), within the same timeframe, can produce opposite effects in different neurotransmitter systems within the same animal. Specifically, GVG administration increased ${ }^{11} \mathrm{C}$-raclopride binding and decreased ${ }^{11} \mathrm{C}$-benztropine binding.

These data support the use of PET, not only for monitoring changes in synaptic neurotransmitter concentrations, but also for assessing the multiple mechanisms of action of new and potentially useful centrally acting therapeutic drugs. These findings have implications for the pathophysiology and pharmacotherapy of disease states that have classically been defined as neurotransmitter specific in origin. Specifically, we can use 
this application of PET as a tool to determine whether the ability of a neurotransmitter to modulate the activity of another functionally linked neurotransmitter is involved in the disease process. By capitalizing on our knowledge concerning neurotransmitter interactions, this would have direct implications for treatment in that therapeutic efficacy could be achieved by indirectly, rather than directly, altering neurotransmitter activity. Potential treatments could be developed for cholinergic, dopaminergic,

thermore, this information may be used to predict the potential side effects of pharmacologic treatment.

An example of a relevant application of this approach is to the study of AD. AD has classically been characterized by a cortical cholinergic deficit. The majority of drug trials have used therapeutic agents (e.g., cholinergic agonists and cholinesterase inhibitors) that were designed to directly reverse this deficiency. With few exceptions, these drugs have not been efficacious. Our PET data suggest that both serotonergic blockade and GABA potentiation may represent two new alternative pharmacologic strategies for enhancing cholinergic activity. Conversely, agents that enhance or decrease serotonergic and GABA activity, respectively, should be used with caution in such patients, as these may produce cholinergic hypofunction resulting in further cognitive impairment. At the level of pathophysiologic mechanisms, the application of the approach described here may be used to characterize the progression of AD. For example, human studiescan be designed to address the effects of chronic cholinergic depletion on other functionally linked neurotransmitters putatively involved in other symptomatology of the disease (e.g., psychiatric features). Finally, the efficacy of atypical neuroleptics and benzodiazepine agonists for treating symptoms in schizophrenia may be linked to the ability of these compounds to block serotonergic receptors and increase GABA activity, respectively. Consistent with our findings, such treatment would result in an increase in cholinergic activity and might be beneficial if cholinergic hypofunction underlies these symptoms, as has been suggested (Tandon and Greden, 1989). Future PET studies will be directed toward addressing such issues in the pathophysiology and treatment of neuropsychiatric disease.

\section{ACKNOWLEDGMENTS}

This research was supported by the U.S. Department of Energy and its Office of Health and Environmental Research; the National Institutes of Health, NS-15638 and NS-15830; National Institute of Mental Health MH-49165 and the National Alliance for Research on Schizophrenia and Depression. The authors gratefully acknowledge the expert assistance of Joanna Fowler, Alfred Wolf, Payton King, Naomi Pappas, Donald Warner, Colleen Shea, Robert MacGregor,
Tom Martin, David Alexoff, Robert Carciello, and Clarance Barrett. We thank Marion Merrell Dow Inc. for the generous supply of GVG.

\section{REFERENCES}

Bartus RT, Beer B, Dean R, Lippa A (1982): The cholinergic hypothesis of geriatric memory dysfunction. Science 217:408-414

Bernheimer H, Birkmayer W, Hornykiewicz O, Jellinger K, Seitelberger $F$ (1973): Brain dopamine and the syndromes of Parkinson and Huntington. J Neurol Sci 20:415-455

Cosi C, Wood PL (1988): Lack of GABAergic modulation of acetylcholine turnover in the rat thalamus. Neurosci Lett 87:293-296

Davis P, Maloney AJ(1976): Selective loss of central cholinergic neurons in Alzheimer's disease. Lancet 2:1403-1405

Dewey SL, Brodie JD, Fowler JS, MacGregor RR, Schlyer DJ, King PT, Alexoff DL, Volkow ND, Shiue C-Y, Wolf AP, Bendriem B (1990a): Positron emission tomography (PET) studies of dopaminergic/cholinergic interactions in the baboon brain. Synapse 6:321-327

Dewey SL, MacGregor RR, Brodie JD, Bendriem B, King P, Volkow ND, Schlyer DJ, Fowler JS, Wolf AP, Gatley SJ, Hitzemann R (1990b): Mapping muscarinic receptors in human and baboon brain using $\left[\mathrm{N}-{ }^{11} \mathrm{C}\right.$-methyl]-benztropine. Synapse 5:213-223

Dewey SL, Logan J, Wolf AP, Brodie JD, Angrist B, Fowler JS, Volkow ND (1991): Amphetamine-induced decreases in $\left({ }^{18} \mathrm{~F}\right)-\mathrm{N}$-methylspiroperidol binding in the baboon brain using positron emission tomography (PET). Synapse 7:324-327

Dewey SL, Smith GS, Logan J, Brodie JD, King PT, Pappas N, MacGregor RR, Martin T, Alexoff D, Shea C, Fowler JS, Wolf AP (1992a): Effects of serotonergic $\left(5-\mathrm{HT}_{2}\right)$ blockade on endogenous dopamine release measured in vivo with positron emission tomography (PET). Soc Neurosci Abstr 18:916

Dewey SL, Smith GS, Logan J, Brodie JD, Yu D-W, Ferrier RA, King PT, MacGregor RR, Martin TP, Wolf AP, Volkow ND, Fowler JS, Meller E(1992b): GABAergic inhibition of endogenous dopamine release measured in vivo with ${ }^{11} \mathrm{C}$-raclopride and positron emission tomography. J Neurosci 12:3773-3780

Dewey SL, Smith GS, Logan J, Brodie JD, Fowler JS, Wolf AP (1993): Striatal binding of the PET ligand ${ }^{11} \mathrm{C}$-raclopride is altered by drugs that modify synaptic dopamine levels. Synapse (In Press).

Euvrard C, Javoy F, Herbet A, Glowinski J (1977): Effect of quipazine, a 5-HT-like drug, on striatal cholinergic interneurons. Eur J Pharmacol 41:281-289

Farde L, Hall H, Ehrin E, Sedvall G (1986): Quantitative analysis of dopamine-D2 receptor binding in the living human brain by positron emission tomography. Science 231:258-261

Gillet G, Armmor S, Fillion G (1985): Serotonin inhibits acetylcholine release from rat striatum slices: Evidence for a presynaptic receptor-mediated effect. J Neurochem 45:1687-1691

Guyenet P, Euvrard C, Javoy F, Herbet A, Glowinski J (1977): 
Regional differences in the sensitivity of cholinergic neurons to dopaminergic drugs and quipazine in the rat striatum. Brain Res 136:487-500

Heimer L, Wilson RD (1975): The subcortical projections of the allocortex: Similarities in the neural associations of the hippocampus, the piriform cortex, and the neocortex. In Santini M (ed), Golgi Centennial Symposium Proceeding. New York: Raven Press, pp 177-193

Holthoff VA, Koeppe RA, Frey KA, Paradise AH, Kuhl DE (1991): Differentiation of radioligand delivery and binding in the brain: Validation of a two-compartment model for $\left[{ }^{11} \mathrm{C}\right]$ flumazenil. J Cereb Blood Flow Metab 11:745752

Jackson D, Bruno JP, Stachowiak MK, Zigmond MJ (1988): Inhibition of striatal acetylcholine release by endogenous serotonin. Brain Res 457:259-266

Koeppe RA, Holthoff VA, Frey KA, Kilbourn MR, Kuhl DE (1991): Compartmental analysis of $\left[{ }^{11} \mathrm{C}\right]$ flumazenil and kinetics for the estimation of ligand transport rate and receptor distribution using positron emission tomography. J Cereb Blood Flow Metab 11:735-744

Lemaire C, Cantineau R, Guillaume M, Plenevaux A, Christiaens L (1991): $\left[{ }^{18} \mathrm{~F}\right]$ Altanserin, a new radioligand for the study of serotonin receptors with PET: Radiolabelling and in vivo biologic behaviour in rats. J Nucl Med 32:22662272

Logan J, Fowler JS, Volkow ND, Wolf AP, Dewey SL, Schlyer DJ, MacGregor RR, Hitzemann R, Bendriem B, Gatley SJ, Christman DR (1989): Graphical analysis of reversible radioligand binding from time activity measurements applied to $\left[\mathrm{N}-{ }^{11} \mathrm{C}\right.$-methyl] $-(-)$ cocaine PET studies in human subjects. J Cereb Blood Flow Metab 10:740-747

Phelps M, Mazziotta JC, Schelbert HR (1986): Positron Emission Tomography and Autoradiography: Principles and Applications for the Brain and Heart. New York: Raven Press.
Quirion R, Richard J (1985): Differential effects of selective lesions of cholinergic and dopaminergic neurons on serotonin-type 1 receptors in rat brain. Synapse 1:124-130

Robinson SE (1983): Effect of specific serotonergic lesions on cholinergic neurons in the hippocampus, cortex, and striatum. Life Sci 32:345-353

Scatton B, Bartholini G (1980): Modulation by GABA of cholinergic transmission in the rat brain. Brain Res 183:211-216

Schechter PJ, Tranier Y, Jung MJ, Bohlen P (1977): Audiogenic seizure protection by elevated brain GABA concentration in mice: Effects of gamma-acetylenic GABA and gamma-vinyl GABA, two irreversible GABA-T inhibitors. Eur J Pharmacol 4:319-328

Seeman P (1987): Dopamine receptors and the dopamine hypothesis of schizophrenia. Synapse 1:139-152

Seeman P, Guan HC, Niznik HB (1989): Endogenous dopamine lowers the dopamine $\mathrm{D} 2$ receptor density as measured by $\left[{ }^{3} \mathrm{H}\right]$ raclopride: Implications for positron emission tomography of the human brain. Synapse 3:96-98

Snyder S, Yamamura HI (1977): Antidepressants and the muscarinic acetylcholine receptor. Arch Gen Psychiatry 34:236-239

Stevens J, Wilson K, Foote W (1974): GABA blockade, dopamine and schizophrenia: Experimental studies in the cat. Psychopharmacology 39:105-119

Tandon R, Greden JF (1989): Cholinergic hyperactivity and negative schizophrenic symptoms. Arch Gen Psychiatry 34:236-239

Vizi ES, Harsing LG Jr, Knoll J (1977): Presynaptic inhibition leading to disinhibition of acetylcholine release from interneurons of the caudate nucleus: Effects of dopamine, Beta-endorphin, and D-Ala ${ }^{2}-P^{-}{ }^{5}$-enkephalinamide. Neuroscience 2:953-961 